\title{
Practice of CDIO Model in the Financial Marketing Course
}

\author{
Xinyan Shi \\ Shenyang Aerospace University, Shenyang, 110136, China
}

\author{
Keywords: CDIO mode; Financial market; Teaching; Practice
}

\begin{abstract}
CDIO educational idea is the latest achievement of international engineering education reform in recent years, combined with the characteristics of financial marketing course and introducing CDIO education idea effectively changed the present situation of the "Disconnection between schools and society"and"Disconnection between teaching and application", it also provides a reference for the practice teaching system construction of financial specialty. Based on the analysis of the financial marketing course teaching problems, referencing CDIO education concept, building a teaching system which includes teaching content, teaching methods, evaluation mechanisms and management mechanism. In order to train modern financial professionals to meet the needs of the society.
\end{abstract}

\section{Introduction}

CDIO refers to Conceive - Design - Implement - Operate, was founded in 2001 by the MIT Department of Aeronautics and Astronautics, four frontier engineering universities (SChalmers University of Technology, Linkoping University in Sweden, Massachusetts Institute of Technology, the Swedish Royal Institute of Technology) develop a new model of cooperation in the development of Engineering Education. CDIO engineering education mode makes students learning project in the form of organic connection between active practice and course. It emphasizes "learning by doing" is the whole process of project life cycle as the carrier, to cultivate students' engineering ability, personal professional morality, academic knowledge and the ability to use knowledge to solve problems, life-long learning ability, teamwork ability, communication ability and the large system control ability. So far, there have been dozens of prestigious universities in the world joining the CDIO organization. CDIO teaching concept was first introduced to China by the academician Pei-hua $\mathrm{Gu}$ in 2005, and established "the Ministry of education CDIO research and practice research group in 2008."At present, our country has nearly more than 40 pilot colleges and universities in the reform of CDIO teaching mode, and other non pilot colleges and universities also have a large number of teachers trying to innovate teaching methods. In recent years, China's higher vocational colleges made many beneficial theoretical research and practical exploration based on CDIO training mode, these studies was not limited to the reform of engineering courses, also appeared in a large number of non-engineering professional use of specific CDIO theory curriculum reform attempt.

\section{The Necessity of the Integration of CDIO Model in the Financial Marketing Course}

《The financial market》 is a scientific research on the operation mechanism and and the laws of the main body of the financial market, giving a priority to study the financial market's operation mechanism and the financial asset pricing issues, comprehensive and systematic introduction to the basic knowledge of the financial markets, is a finance professional backbone course for the 21st century. This course has a deep content, involving a wide range and closely linked with the actual economic life.But in the traditional teaching methods mainly focus on imparting theory knowledge, emphasizing the system theory,the stiff, simple teaching methods of theoretical knowledge can make students feel boring, can't excite students' interest in learning or mobilize students' study enthusiasm.Making the CDIO teaching concept into the curriculum teaching, can better realize the combination of theory and practice, fully mobilize the enthusiasm of students to learn and cultivate the comprehensive ability of students. 


\section{The Practice of the Reform of Financial Marketing Course Based on CDIO Model}

At present, higher education in theoretical teaching is mainly based on Teachers' Teaching. In practice teaching, mainly in the verification test and simulation training. Although to a certain extent, use the integration of" teaching, learning and doing" teaching methods, but ignore the cultivation of students' independent innovation and open line thinking. With the CDIO teaching mode, breaking in accordance with the existing line of teaching concept and actively encouraging students to cultivate students' innovative thinking. Students according to the given conditions, initiative thinking, active design, try to achieve the physical operation. Integrating the CDIO concept into the financial marketing course, reform teaching methods. Specific measures can be started from the following aspects:

The Integration of Teaching Design. In traditional education, the inspection way draws student's attention to master the theoretical knowledge and apply the local skills. But cannot have a complete understanding of the knowledge, not to mention the flexible application of these knowledge. For this reason, we adopt the CDIO engineering education idea to realize the new way of teaching and practice innovation. Improve students' practical skills by using project based learning in CDIO, deepen the understanding of theoretical knowledge, through the effective integration of internal and external knowledge, to achieve the integration of the training effect. The integration of instructional design is the foundation of the project driven learning based on the CDIO concept. Due to the application of professional multidisciplinary knowledge in the project, so it needs to integrate several courses related to financial markets, extract associated knowledge points, construct the integrated teaching program. In the course of teaching and project development of financial market, involving the course of study with probability and statistics, finance, and its related follow-up courses are securities investment, international finance, futures and options, etc. This integrated teaching program which integrates the course of study, financial market and the relevant knowledge points in the following courses can make the students have a complete understanding of the professional basic subjects.

Project Driven Learning. Project driven learning methods require the course of the study, in order to complete the project with a certain degree of complexity as the main goal, the project contains the teaching content and the integration of teaching design goal, students through a series of CDIO process to complete the project. This learning method not only deepen the students' understanding of the theoretical knowledge, but also cultivate the students' ability in all directions.

Combining with the course of financial marketing course, the implementation process of project driven learning using CDIO teaching model is composed of 6 core steps, each stage has a different implementation content, focus on different skills training. Specific stages of the content are as follows:

(1)Curriculum theory teaching stage (I).Learning of knowledge points in financial market, mainly including: the currency market consists of seven sub markets, interbank lending, buy-back, bank acceptance bill, etc; the capital market consists of three sub markets, shares, bonds, funds; the foreign exchange market; the derivative market, interest rate mechanism and bonds' value analysis, common stock's value analysis, etc.

(2)Preparatory stage ( II).Teachers will combine above-mentioned knowledge points with the reality of economic phenomena, and the social and economic problems of the hot spots, set several projects (micro analysis report or case)and publish the content and requirements of the project, students according to the need of the project team and the team elected the main person responsible for the project;

(3)Project conception stage (III).Each group will analyze the project objectives, research and forecast projects to achieve the objectives of the project;

(4)Project design stage (V).Students will independently determine the team division of labor, prepare project reports. (Report the relevant program developed by the project and its assessment);

(5)Project implementation stage (VI).Team members are the main body, arrange the micro project report, students will show their achievements centrally. 
(6)Operation and evaluation stage(VII).Teachers and other students are not only the audience, but also the judges. They will ask questions on the content of the report, sum up and propose shortages and suggestions, group assessment of the project implementation of specific solutions to what the problem, given what recommendations, summary of the project to carry out the main harvest and related reflection, etc.In the project driven process, students' desire about autonomous learning will be inspired easily. Through the development of the project, course learning process and project implementation process will form a positive interaction

Cultivate Students' Autonomous Learning Ability. What is called that the learner is autonomous, as learners are willing to take responsibility for their own learning. It requires learners to have cognitive strategies. Before learning to plan their own learning tasks, learning process to monitor the correction of their own learning methods, after study they can evaluate their progress. The CDIO outline of a clear description of the desire for "knowledge and lifelong learning" ability of the training, at the same time requires the student to learn "the management of time and resources", and learner autonomy is to adapt to the needs of lifelong learning and independent learning, Autonomous learners are able to take the initiative to assume the responsibility of learning, learn to solve problems in their own learning, and don't take the time to wait for the teacher to give the answer or provide the resources, this conforms to the CDIO standard (CDIO standard 8). The cultivation of learners' autonomous learning ability can be carried out by the following methods:

First, learning strategy training, learning strategies are "learners for effective access, storage, retrieval and use of information used by the various programs, behavior, steps," that is, to learn and adjust the various measures taken by learning. Learning strategies can enable students to choose learning strategies according to their personal preferences, so that they can plan, monitor and evaluate their own learning.

Second, students participate in curriculum design. Research shows that if the students to provide a suitable for their own development of the soil, such as pleasant learning atmosphere, independent decision-making, participation in curriculum design and assessment of the rights and so on. Learners' reflection, decision making and independent learning ability of independent action can be continuously improved. Curriculum design mainly includes two aspects: the first is to determine the learning needs and goals, the second is a clear way to achieve the goal. This process can enable students and teachers resonate in many aspects of teaching, Make them aware of the importance of positive, active learning attitude and action to improve their ability. Therefore, it will be more active in the classroom activities, the harvest will be more.

Third, creating a personalized learning environment. Emphasize personality differences, allowing learners to develop according to their own characteristics. Teachers according to the student's individual situation, help them to set learning goals, understand evaluation methods. For example, the beginning of school, the teacher announced the assessment method of course, the scores given including learning attitude, routine testing, project completion, classroom discussion and practice achievement of several parts, each student can according to their own goals, claim the learning task.

Set a Diverse Practice Content. Some of the content of financial market has a strong practicality, but due to the financial market is covered by a large market type, teachers combined with different market characteristics set up a variety of differentiated practice content.

First, Make full use of the Internet for teaching. During the class, using the internet combined with teaching content, introduction, watch videos, pictures related to the class, the latest events and comments.,etc. For example, in the introduction section to the students 《Wall Street》and 《The Power Of The Company》, let the students have an intuitive understanding of the importance of financial markets. When talking about the reasons for the appreciation of the RMB is discussed, introducing 《The War Of The Coin》series. In talking about the "RMB exchange rate system reform", introducing students to watch some special lecture video in the Phoenix finance online, to the people's Bank of China website to learn about the latest RMB exchange rate policy. Make full use of network teaching to help teachers timely and comprehensive understanding of the latest 
international financial information and international financial theory development, timely update the teaching contents, helps students to the latest hot issues have a comprehensive understanding.

Secondly, the use of financial experimental courses. Can make full use of school financial laboratory experimental teaching, the students according to the experimental requirements and problems to arrange the experiment, so that students in the master of Finance Based on the basic principle, have personal experience of the actual business. For example, in the financial market, interest rate and foreign exchange trading, derivatives arrangements the financial experiment course, which can not only improve the students' practical ability, but also increase the students' perceptual knowledge of knowledge.

Third, encourage students to participate in all training items. The securities market is more important in the financial market and the most familiar market. The CDIO concept can be transplanted to the securities market practice teaching plan, project course, namely the securities market real training project. Although the simulation of the stock market transactions, but also can play a role in practice. But the students do not understand the securities market account, the specific process of trading, they cannot experience the real state of the trading place. Therefore, in view of the securities market to lower the threshold, the organization has the economic ability of the students to participate in all training programs, is the practice of project teaching implementation of students and the financial market "zero distance". Students to participate in the voluntary principle,5-10 people a group, the students to raise a certain amount of its own funds, and the management of the funds and operations. According to its own funds to benefit sharing, risk sharing principle of operation, investment object can be a stock or fund, investment cycle for 2 to 3 months, at the end of the semester ended, the project team to complete the investment analysis and evaluation report. All training programs can let students in learning theory knowledge to experience the process of practice.

\section{Summary}

The CDIO to comprehensively enhance the comprehensive ability of students as the goal, always run through the theory with practice, the implementation of integrated education, introduce the concept of CDIO in China World Trade Center professional practice teaching system, popularization and application of CDIO education model, the reform and innovation of the course teaching of financial market in China, improve financial talents training quality has very important practical significance. At the same time, the CDIO concept is still mainly used in engineering professional talent training, the application of higher education in our country is not long, in the economic profession in the use of CDIO model is less. Due to the lack of experience, in the future, we need to gradually explore and practice to improve and perfect.

\section{References}

[1] Wang Gang, Reading and Thinking of CDIO engineering education model, the Chese Higher Education, 5:86-87.

[2] Tangquan Li, Lu Xiaohua, Xiong Guangjing Outline of CDIO engineering innovative talents training, Higher Education Research.2008, 31(4):15-18.

[3] Diana Farrell, Andrew J. Grant, China's Looming Talent Shortage. The Mckinsey Quarterly, 2005, (4):70-79. 